\title{
SEMI-RIGID STEEL FRAMES LOCATED IN SEISMIC AREAS
}

\author{
Alíz Éva MÁTHÉ1 ${ }^{1}$ Cristian CIPLEA ${ }^{2}$ \\ Technical University of Cluj-Napoca, Faculty of Civil Engineering, Structural Mechanics Department, Cluj-Napoca, \\ Romania \\ ${ }^{1}$ aliz.mathe@mecon.utcluj.ro \\ ${ }^{2}$ cristian.ciplea@mecon.utcluj.ro
}

\begin{abstract}
The realistic response of the steel frames cannot always be investigated with idealized rigid or articulated joints. For sideways loads, significant calculation errors may occur if the modeling of the joints does not take into account their most realistic behaviour. The use of semi-rigid joints, both in design and construction, can result in favourable structural properties in the case of steel frames, especially in seismic areas.
\end{abstract}

Keywords: seismic response, steel frame, semi-rigid.

\section{About semi-rigidity}

Conventional analysis of frames is usually performed under the assumption that a connection joining a beam to a column is either infinitely rigid or perfectly pinned (Figure 1.). The experimental results show that the actual behaviour of joints is far from the above idealization. All connections transmit some moments and exhibit a certain degree of flexibility.

The concept of semi-rigid or flexible connections is recognized in several national codes for steel structures. There are several mechanical solutions for a semi-rigid beam-to-column connection ranging from fully rigid, semi-rigid, to pinned state (Figure 1.).

\section{Modeling and behaviour of semi-rigid connections}

The behaviour of the connection is described by a non-linear moment-relative rotation relationship, which is usually determined through experiments. Numerous experimental results have shown that the connection bending moment $M$ - relative rotation $\Phi$ relationships are non-linear over the entire range of loading for almost all types of connections.

The fundamental role of the constitutive relation bending moment $M$-relative rotation $\Phi$ (or $\Theta r)$ have to be properly dealt with. Several analytical models have proved to adequately agree with the results of experimental investigations. Among
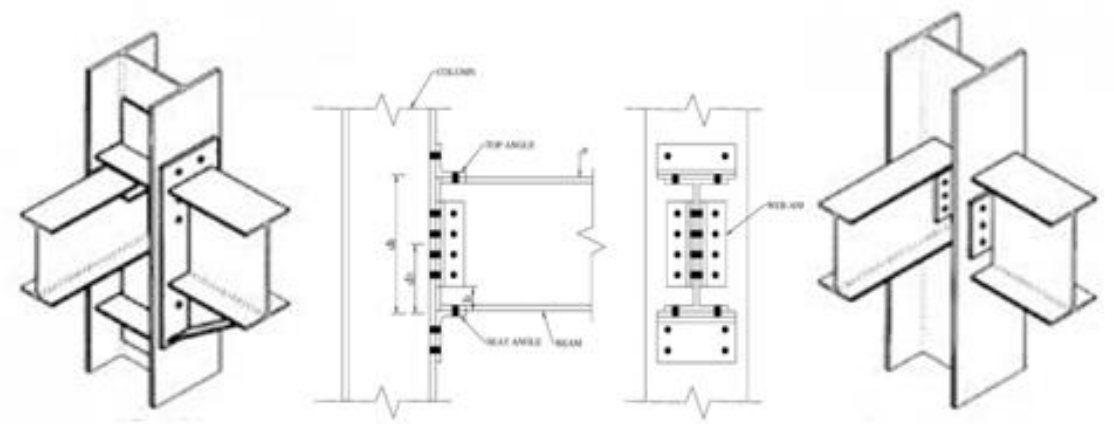

Figure 1. Fully rigid, semi-rigid and pinned connection types 
the most popular analytical models is the Frye Morris polynomial function [1]:

$$
\theta_{r}=C_{1}(K M)^{1}+C_{2}(K M)^{3}+C_{3}(K M)^{5}
$$

Here, $C$ are curve fitting constants, $K$ is a dimensionless factor depending on the geometry of the connection, while $M$ is the bending moment at the beam-to-column interface and $\Theta$ is the relative rotation of beam section against the column section.

Power model (2) proposed by Kishi and Chen [2] has the following generalized form:

$$
M=\frac{k_{0} \theta}{\left\lfloor 1+\left(\frac{\theta}{\theta_{0}}\right)^{n}\right]^{\frac{1}{n}}}
$$

Here, $\Theta_{0}=M_{u} / R_{k i}$, where $R_{k i}$ is the initial stiffness of the connection, $M_{u}$ is the ultimate bending mo-

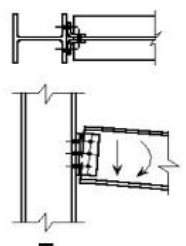

I

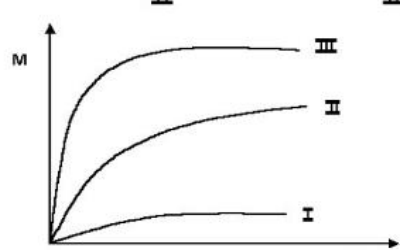

Figure 2. A general aspect of bending moment $M$-relative rotation $\Phi$ associated with semi-rigid connection

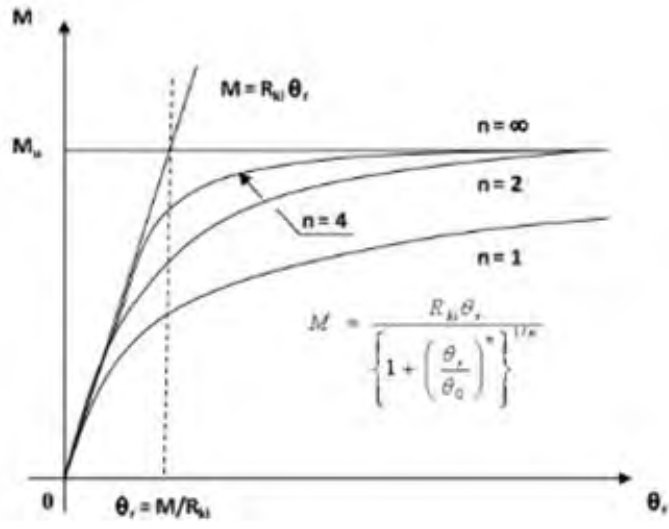

Figure 3. Constitutive $M-\Theta_{r}$ in of shape parameter ment capacity, $\mathrm{n}$ is a shape parameter and $\Theta_{0}$ is a reference plastic rotation [3, 4].

Richard and Abbot [5] proposed a three parameter model in the form:

$$
R_{k}=\frac{d M}{d \theta_{r}}=\frac{R_{k i}}{\left[1+\left(\frac{\theta_{r}}{\theta_{0}}\right)^{n}\right]^{(n+1) / n}}
$$

The shape parameter $n$ plays an important role in these (2), (3) constitutive relations, as illustrated in Figure 3.

Figure 4. illustrates the difference between the responses of a simple, two level steel frame, where the ideal rigid joints are used instead of semi-rigid joints. There are also quite different phenomena in the case of cyclic loads, as the semi-rigidity is followed by some plasticization (Figure 5.).

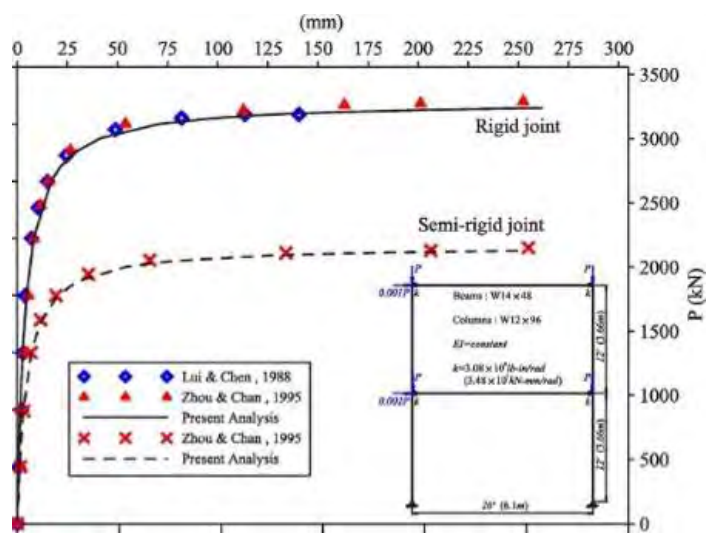

Figure 4. Rigid and semi-rigid in the case of a simple frame

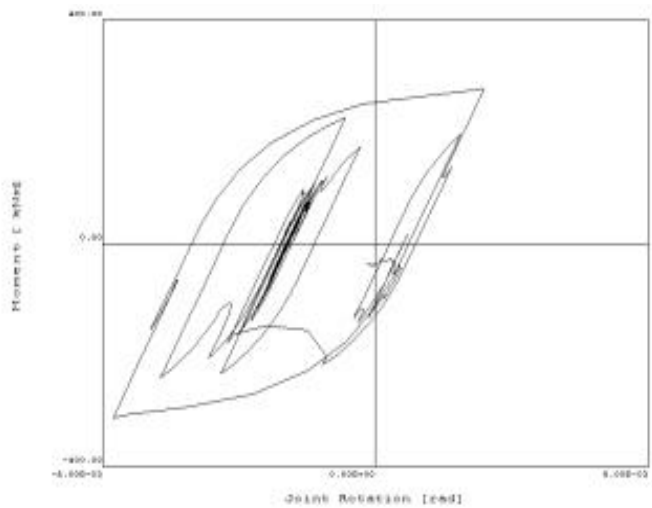

Figure 5. Hysteretic constitutive semi-rigid relationship 


\section{Standardization of semi-rigidity}

The experimentally established constitutive $M-$ $\Phi$ relationship needs a number of mechanical parameters to be assessed initial stiffness, rotational capacity, design limits to be applied (Figure 6.).

The large spectrum of semi-rigid behaviour mainly under seismic action - is due to the kinematics of the semi-rigid connection (Figure 7.): rotation $\Theta_{c}$ of column section differs from rotation $\Theta_{b}$ of adjacent beam section. The different rotation of the two structural components of the connection generates the relative rotation $\Phi$ (Figure 8.).

Experimentally obtained data may, indeed, assign the state of the beam-to-column connection, as: rigid, semi-rigid or pinned (Figure 6.). The design activity has to simplify and adopt models of semi-rigidity if it is to be incorporated in practical design activity [6, 7]. Considering the semi-rigidity of the connections leads to significant differences (Figure 3. and 4.) between numerical results, that cannot be neglected $[6,7,8]$.

The real problem of steel structures located in seismic areas is their behaviour under seismic action $[9,10,11]$. In these situations seismicity induced lateral displacement and, generally, a specific dynamic behaviour requires a hysteretic

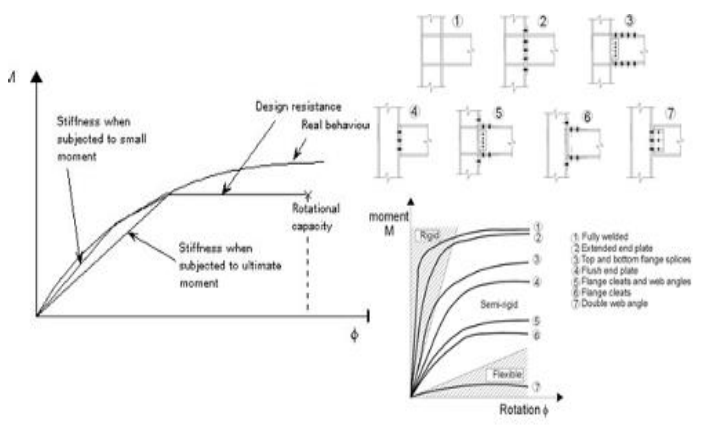

Figure 6. Experimentally assessed parameters and assigned a state of semi-rigidity

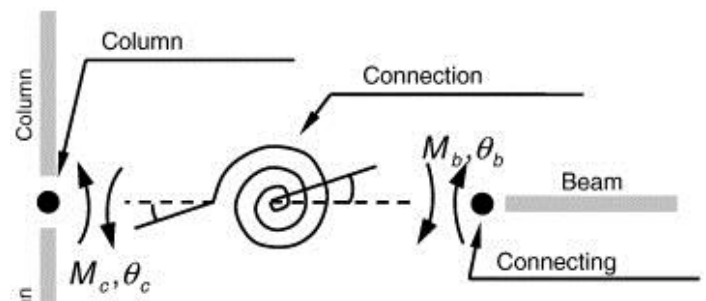

constitutive bending moment - relative rotation relationship, due to which the response of the structure may differ significantly (Figure 10).

\section{Conclusions}

Semi-rigidity is a clearly defined state of multi-story structures located in seismic areas and it must be approached accordingly. The specific behaviour of semi-rigidly connected structures cannot be approximated or neglected. The hysteretic nature of the constitutive bending moment - relative rotation relationship confers a dissipative property to semi-rigid steel structures. Dissipation of seismically induced energy is, in turn, a positive feature of these special structures.

\section{Classification of joints by initial stiffness}

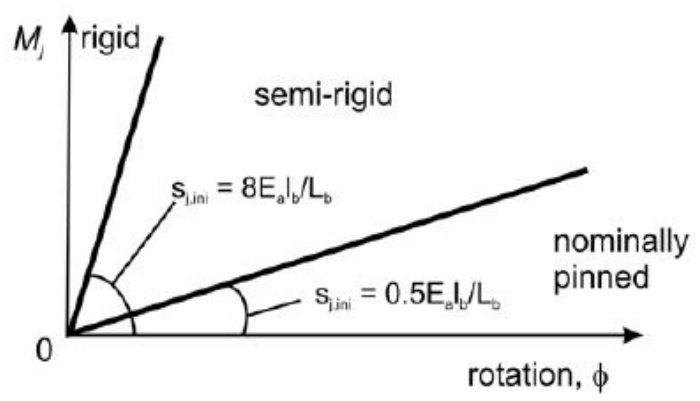

Figure 8. Classification of node connections based on calculated initial rigidity

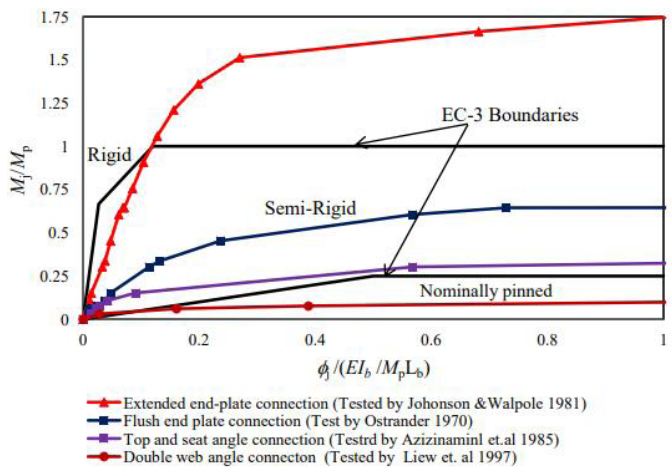

Figure 9. From experiment to standardization
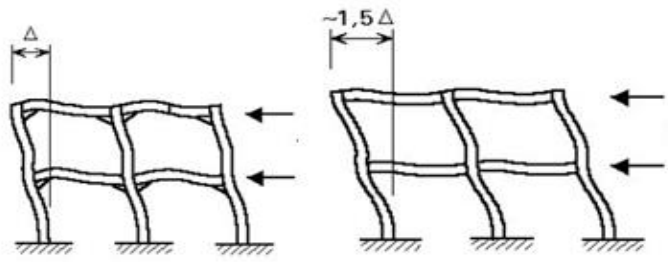

Figure 7. Rotational semi-rigidity scheme 


\section{References}

[1] Frye M.J., Morris G.A.: Analysis of flexibly connected steel frames, Canadian Journal of Civil Engineering 2/3. (1975) 280-291.

https://doi.org/10.1139/175-026

[2] Kishi N., Chen W. F., Goto Y.: Effective length factor of columns in semirigid and unbraced frames. Journal of Structural Engineering 123/3. (1997) 313-320.

https://doi.org/10.1061/(ASCE) 0733 9445(1997)123:3(313)

[3] Kim Y., Chen W. F.: Practical analysis for partially restrained frame design. Journal of Structural Engineering 124/7. (1998) 736-749.

https://doi.org/10.1061/(ASCE) 0733 9445(1998)124:7(736)

[4] Goto Y., Miyashita S.: Classification system for rigid and semirigid connection. Journal of Structural Engineering - ASCE, 124/7. (1998) 750-757. https://doi.org/10.1061/(ASCE) 0733 9445(1998)124:7(750)

[5] Richard R. M., Abbott B. J.: Versatile Elasto-Plastic Stress-Strain Formula. Journal of the Engineering Mechanics Division, 101/4. (1975) 511-515.
[6] EN 1993-1-1 (2005): Eurocode 3. Design of Steel Structures. Part I: General rules and rules for buildings. Comite European de Normalisation (CEN) Brussels, Belgium, 1992.

[7] American Institute of Steel Construction: Manual of steel construction: allowable stress design. Chicago, 1989.

[8] Faella C., Piluso V., Rizzano G.: Structural Steel Semirigid Connections. CRC Press LLC, Boca Raton, 2000.

[9] Máthé A.: Nonlinear geometrical elastic analysis of semirigid connections. Phd thesis, Technical University of Cluj-Napoca, 2009.

[10] Alexa P., Máthé A.: Energy state of multi-story structures equipped with passive protection. In: International Colloquium on Stability and Ductility of Steel Structures (SDSS'2016) (Eds.: Dubina D., Ungureanu V.), Timisoara, Romania, 2016. 851-858.

[11] Hensmann J. S., Nethercot D. A.: Numerical study of unbraced composite frames: generation of data to validate use of the wind moment method of design. Journal of Constructional Steel Research 57/7. (2001) 791-809. http://doi.org/10.1016/S0143-974X(01)00008-6 